\title{
Empirical Analysis of Possible Alternative Sustainable Financing Options for Primary Health Care Services in Kenya
}

\author{
Timothy C. Okech $(\mathrm{PhD})$ \\ Chandaria School of Business, United States International University-Africa
}

\begin{abstract}
The Kenya government has over the years reiterated its commitment towards the provision of quality primary health care (PHC) to her populace. The various macroeconomic performance experienced in the late 1980s and early 1990s, however affected the government's ability to sustain the continued provision of PHC. This is not only demonstrated by the high out-of-pocket spending but also low budgetary allocation currently estimated at less than ten (10) percent. The funding levels have negatively affected the ability of the poor to access primary health care while the quality of health care provided has equally been a concern as witnessed by high incidences of lack of essential drugs and other medical supplies, low morale amongst the health personnel involved in the provision of primary health care, lack of medical equipments in most facilities and skewness in the deployment of staff countrywide. The objective of the study was therefore to examine the various alternative financing mechanisms to mitigate against the trends, Since various financing mechanisms have been suggested for consideration. In the study it was found that providers of these services prefer financing mechanisms that pool funds together to ensure that the poor and other vulnerable are cushioned against the catastrophic health expenditure. Other mechanisms favored included establishment of specific taxes to finance health care, and where possible consider issuance of health infrastructure bonds to facilitate construction of modern health facilities across the country within the decentralized framework of counties. Although these mechanisms sound promising, their success will depend not only on political and leadership commitment but also on the ability to identify the poor and where possible provide the necessary safety nets such as waivers and exemptions. It will also be necessary to establish the necessary legal framework that will spearhead the collection and management of the funds collected.
\end{abstract}

Keywords- Primary health care, financing mechanisms, Prepayment schemes, catastrophic health expenditures

\section{I.1 Background of the Problem}

\section{INTRODUCTION}

The Kenya government has over the years continued to develop and implement national health policies and strategies necessary for enhancing the financing of a well-functioning health system. This was however partly affected by the economic down-turn experienced in the late 1980s and early 1990s. This in the process affected the government's ability to continue providing public goods including PHC. Additionally, the demand for PHC overstretched the available supply and soon it was evident that the available resources were insufficient to fully finance the continued provision of quality PHC effectively. At the same time, the budgetary allocation started to dwindle, while donor funding was subjected to realization of certain macroeconomic conditions. This led to the introduction of alternative financing mechanisms such as user fees, whose main objective was cost recovery. The introduction of user-fees coincided with the marked deterioration of health indicators in the country, frequent shortages of drugs and commodities, as well as low retention of the health workforce.

The policy change was however, considered pro-poor if used to improve access to quality health care, and help reorient public financing towards serving poor and other vulnerables. Following the policy initiation, there were however concerns that the fees could limit utilization of PHC particularly by the poor especially in low income countries. It was however, argued that the charges should be accompanied by appropriate safety nets that would caution the poor and other vulnerables. This policy change has however, over the years been seen as negatively affecting access to quality PHC in terms of delays and also subject to sloppy management in general (GoK, 2010, GoK, 2005). Studies show that user fees through out-of-pocket (OOP) expenditure represent a major source of health care financing contributing at least $36 \%$ of total health expenditures (GoK, 2010; GoK, 2011). This kind of expenditure according to 2010 report by the government leads to the impoverishment of an estimated 1 million households, while a further $39 \%$ of sick people fail to seek treatment. Similarly, data provided by the Public Expenditure Tracking Survey of 2008, indicates that an average of $30 \%$ 
(range 0\%-65\%) of earmarked financial resources from government sources do not reach health centres and dispensaries. This is a clear indication that PHC is adversely affected. Consequently, the risk of financial catastrophe and impoverishment is expected to worsen especially among the poor and if necessary safety nets or other financing mechanisms are not initiated and implemented, the realization of universal coverage may take longer than expected.

There is also evidence that public financing is skewed towards other sectors compared to the health sector. For instance in a report by Gitahi (2011), it was observed that out of Kshs 236.6 billion allocated to social sector in 2009/2010, the Ministry of Education received 73.8\% while the Health Sector received a paltry $16.0 \%$ of the allocation (see also GoK, 2010). This allocation according to Gitahi (2011) has continued to contribute towards a funding gap in equipment, drugs, non-pharmaceuticals, health personnel and health infrastructure countrywide (see also GoK, 2010). Although in nominal terms, the overall government expenditure on health increased in the last few years, from 16.4 billion in 2003/04 to 39.9 billion in 2009/10 (USD 13.6 per capita), health financing in Kenya continues to pose a major challenge in health care delivery. This trend continues to be realized despite the government's commitment in various policy documents including Kenya Vision 2030 and the MTEF of 2008. In addition, this level of funding is well below the Abuja declaration target of 15\%, the Economic Recovery Strategy of 12\% and the WHO recommended level of US\$ 44 per capita on average (unweighted) in 2009, rising to a little more than US\$ 60 per capita by 2015 for low income countries (GoK, 2009, WHR, 2010). Based on the foregoing discussion, the study sought to examine empirically, alternatives sustainable financing of public health care in the Kenya's context.

\subsection{Situational Analysis}

Kenya's health indicators though showing a mixed trend since independence in 1963 to present, they continue to lag behind those of the rest of world including sub-Saharan Africa (SSA). During the period, life expectancy rose from about 43.4 years (1960) to 62 years (1990), before declining and stabilizing at about 52 years (2006). Infant mortality on the other hand dropped from 122 per 1,000 live births (1960) to 63 in 1990, before rising to 83 in the year 2000, followed by a drop to the current level of 52 (GoK, 2010). The estimates for the under-five-year mortality rate over the same period were 204 per 1,000 live births, 93, 134 and 77 respectively. Finally, maternal mortality rates still remain high at 414 per 100,000 live births, 650 in 1990 and 1,000 in the year 2000. Evidently, these rates are far above the targets set for the MDGs for the country. Life expectancy (LE) at birth in Kenya though estimated at a low of 45.2 years during the previous policy period, this has is estimated to have risen, up to 60 years by 2009 (World Health Statistics, 2009). This trend was reflected across all age groups, with stagnation/worsening of the health situation seen across all age.

In the country, most disability adjusted life years (DALY) are lost as a result of a double epidemic of communicable and non-communicable diseases: primarily malaria, HIV/AIDS, tuberculosis, diabetes, heart disease and injury. In common with all these disease conditions is the plethora of evidence confirming that they can all be prevented, using simple cost effective interventions. In the country, there exist compounding geographical, urban-rural and poverty related gradients in the prevalence of these conditions, as well as health outcomes. Malaria is considered to account for almost half of morbidity in the country. It is ranked the third cause of death and an estimated $70 \%$ of the population is at risk of infection; with on average about 93 children dying every day from malaria infection.

Currently more than 2.2 million Kenyans are living with HIV/AIDS while there are over 2 million HIV/AIDS related orphans in the country. AIDS is the number one cause of mortality in Kenya. Additionally, tuberculosis has assumed a higher epidemiological significance in the country since the advent of HIV/AIDS. It carries an annual risk of infection of $1.2 \%$ or about 480,000 new cases (2009 national population). Multi-drugresistant strains are an emerging public health problem that will greatly increase the cost of treatment and mortality rates. An estimated $60 \%$ of HIV cases are co-infected with tuberculosis. Notification rates in the country are low at less than $20 \%$. Respiratory infections and diarrhea are ranked first and second, respectively, as the highest causes of death among children 5 years of age and under. Neonatal deaths from various causes are by far the most frequent cause of death among children in this age group. Lastly, in 2001 it was estimated that $53.8 \%$ of deaths in low income countries, including Kenya, were as a result of non-communicable disease; mainly cardiovascular disease, injuries, diabetes and cancer. Similarly, $48.9 \%$ of DALYs (burden of disease) were attributed to non-communicable diseases (GoK, 2008; GoK, 2010).

\subsection{Health Sector Reforms}

The government has over the years recognized that the healthcare financing system is the linchpin of the healthcare system. Improving the financing of the sector is thus been considered a key priority over the last two decades. In this regard, various policies and strategies have been initiated over time by the government with support of various key stakeholders. Among these include Health Policy Framework Paper, National Health Sector Strategic Plan I \& II, Vision 2030 and the constitution. In this sub-section, a brief overview of the reforms is discussed. 
Empirical Analysis of the various alternative sustainable....

\subsubsection{The Health Policy Framework}

In 1994, the government developed the Health Policy Framework of 1994 and two successive 5-year National Health Sector Strategic Plans of 1999-2004 and 2009-10 set the targets and processes driving the health sector development, as well as healthcare service delivery. In the Health Policy Framework of 1994, the aim was to introduce reforms, in relation to the way the healthcare services are not only organized but also financed, delivered and evaluated. Key to the realization of these goals was equitable allocation of government resources to reduce disparities in health status; increased cost-effectiveness and efficiency of resource allocation and use. Others were enhanced regulatory role of the government in health care provision; creation of an enabling environment for increased private sector as well as community involvement in service provision and financing; and increase and diversify per capita financial flows to the health sector.

In the NHSSP II, important approaches and innovations such as the concept of Kenya Essential Package of Health (KEPH), the Community Strategy, the Joint Framework of Work and Financing (JPWF) an essential element for entrenching the Kenya Health Sector-Wide Approaches (KHSWAp), and finally, the Annual Operational Planning process were emphasized. To operationalize the Health Policy Framework, the Ministry of Health $(\mathrm{MOH})$ developed the Kenya Health Policy Framework Implementation Action Plan while at the same time established the Health Sector Reform Secretariat (HSRS) in 1996 under a Ministerial Reform Committee (MRC) to spearhead and oversee the implementation process. Similarly, a rationalization programme within the $\mathrm{MOH}$ was also initiated. These policy initiatives were aimed at responding to among others the financing of the public health sector as a bold step towards enhancing access to quality care amongst the poor and other vulnerables.

As a means of increasing financial access, the National Hospital Insurance Fund Act was repealed and new legislation enacted in 1998. The new Act provided for the expansion of the benefit package to, among others, cover out-patient healthcare services, expand coverage to include the informal sector, and provisions for improving governance. However, NHIF service coverage was not expanded at that time, and the population continued to experience even greater constraints in affording the user-fees applicable in the public sector, while the prospects of meeting any of the health goals, including MDGs, remained remote. The situation became critical in 2002, forcing the Ministry of Health to drastically rethink about the user-fees policy. In the process, user fees were abolished in the health centres and dispensaries, leaving only the registration fees of KSh 20 and KSh 10, respectively otherwise known as 10/20 Policy.

\subsubsection{The Kenya Vision 2030 and the MTEF 2008-2010}

Further commitments by the Kenyan government in pursuing reforms are also reiterated in the Kenya Vision 2030 and operationalized in the Medium Term Expenditure Framework (MTEF) of 2010. In the documents, the central role of health as a key pillar in driving Kenya to be a globally competitive and prosperous nation with a high quality of life equal to that of a middle-income country, by 2030 is emphasized. The government has further affirmed its commitment of providing "equitable and affordable healthcare at the highest affordable standard" to its citizens in the MTEF. These are to be realized among other initiatives access supported by availability of services and financial access - targeting affordability; This was realized through the provision of robust health infrastructure; strengthening health service delivery (especially through human resource development strategies); development of health financing instruments such as health bonds, more effective risk-pooling by transforming NHIF into National Health Services Trust (NHST) while at the same time ensure AID effectiveness and harnessing the informal sector financing potential. Other mechanisms were enhancing revenue collection and broadening the benefit package.

\subsection{Health Financing in Kenya, Human Resources and Health Infrastructure}

\subsection{General Financing Sources}

The healthcare financing system is not only complex but equally fragmented with respect to how revenues are raised, managed and disbursed to various spending levels. The GOK funds the health sector through budgetary allocations to the MOH and related government departments. However, tax revenues are unreliable sources of health finance, because of macroeconomic conditions such as poor growth, national debt, and inflation, which often affect the allocation to the health sector. A manifestation of the health budget shortfalls is the widespread lack of adequate drugs and pharmaceuticals, staff shortages, and poor maintenance of equipment, transport, and facilities. Over the past two decades, the GOK has pursued a policy of cost sharing to bridge the gap between actual budgets and the level of resources needed to fund public health sector activities. The revenue from the cost-sharing programme has continued to grow in absolute terms and as a percentage of the recurrent government budget. In 2002-03, cost sharing contributed over 8 percent of the recurrent expenditure and about 21 percent of the non-wage recurrent budget of the $\mathrm{MOH}(\mathrm{GoK}, 2010)$. This process is summarized in figure 2.1 
Empirical Analysis of the various alternative sustainable....

Figure 2.1: Healthcare Financing in Kenya

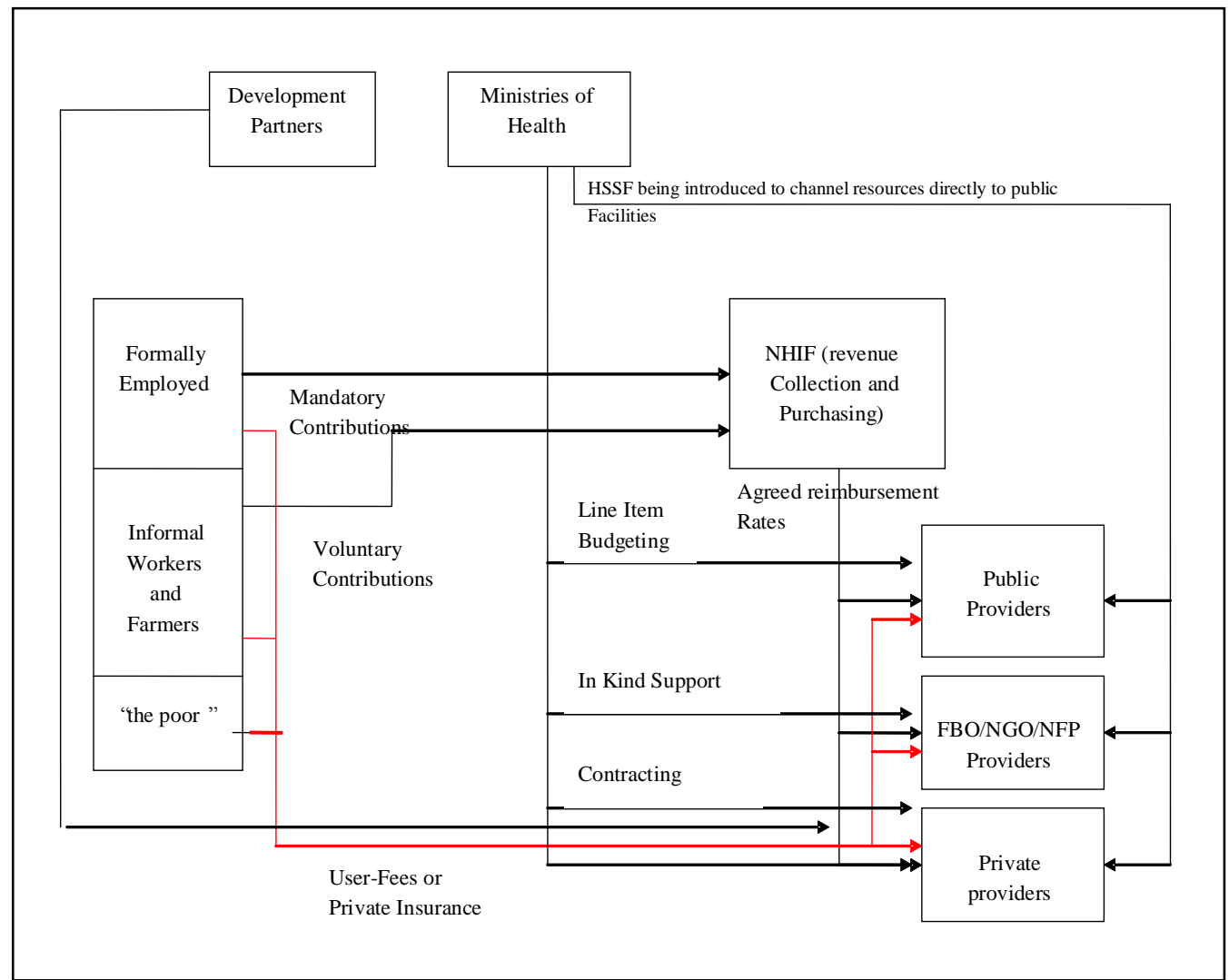

Source: MoH, 2010

Key: $\quad$--- Private funds

---- Public funds

Reviews of public expenditures and budgets in the country show that total health spending constitutes about 8 percent of the total government expenditure while recurrent expenditures have been consistently higher than the development expenditures, both in absolute terms, and as a percentage of the GDP. Studies reveal that recurrent expenditure is mostly on program management including wages, with very little spend on drugs and others medical supplies. Also, the per capita expenditure falls short of the Government of Kenya's commitment to spend 15 percent of its total budget on health based on the Abuja Declaration of 2001. The under-financing of the health sector has impacts negatively on the poor and other vulnerables on their ability to access quality health care. Overall health system expenditure has significantly increased in nominal terms, from 17 US\$ per capita, to an estimated 40US\$ by 2010 (GoK, 2010). This expenditure increase is primarily driven by Government and donor resource increases, with proportion of household expenditures reducing as a proportion of the total expenditures. There is, however, no real increase in health system resources, with health expenditures as a proportion of GDP, and public expenditures as a proportion of general government expenditures remaining stagnant during the policy period $(\mathrm{GoK}, 2010)$.

\subsection{Total Health Expenditures}

Reports show that budgetary allocations to the Ministry of Health between 2000 and 2005 have increased steadily in absolute terms from Ksh. 12 billion in 2000-01 to Ksh. 23 billion in 2004-05. Recurrent expenditures have increased both in absolute terms and as a proportion of total GOK spending and GDP, while development expenditures are somewhat variable, reflecting fluctuations in donor spending (GoK, 2005b). Although the government health budget has increased in absolute terms - from KSh 15.3 billion in 2003/4 to KSh 34.4 billion in $2007 / 08^{1}$ (MPER, 2009) - it has declined significantly as a share of government spending from $7.66 \%$ in $2004 / 05$ to $7.3 \%$ in $2007 / 08$ (including on budget donor funding), and from $8.0 \%$ in 2002 to $5.2 \%$ in 2006 (focusing solely on government financing). This suggests that, as on budget donor funding has increased, domestic funding has been withdrawn casting doubts on sustainable financing of health care in the country. As noted elsewhere, these levels remain well below the Abuja Declaration commitment figure of $15 \%$ and the Economic Recovery Strategy target of spending 12\% of the budget on health. Similarly, per capita

\footnotetext{
${ }^{1}$ Of this recurrent expenditures accounted for some KSh 23.5 billion
} 
Empirical Analysis of the various alternative sustainable....

government spending has remained at less than US\$ 8, which is below the average for sub-Saharan Africa, with total health expenditure, as a percentage of GDP, at just $4.8 \%$.

In spite of the budgetary allocation to the ministry, the actual spending is skewed in favor of tertiary and secondary care facilities, which absorb 70 percent of health expenditures notwithstanding their proximity by the poor and other vulnerables. Yet primary care units, being the first line of contact with the population, provide the bulk of health services and are cost effective in dealing with the disease conditions prevalent in communities. Health personnel expenditures on the other hand are high, compared to expenditures on drugs, pharmaceuticals, and other medical inputs such as medical equipment and supplies an indication that budgetary allocation is skewed towards program management as opposed to preventive and curative management. Recent estimates reveal that personnel spending accounts for about 50 percent of the budget, leaving 30 percent for drugs and medical supplies, 11 percent for operations and maintenance (O\&M) at the facility level and 10 percent for other recurrent expenses.

Expenditures for curative care constitute more than 48 percent of the total $\mathrm{MOH}$ budget. Donor contributions to the health sector have been on the increase, rising from 8 percent of the health budget in 199495 to 16 percent in the fiscal 2001-2002. In some years, donor contributions accounted for over 90 percent of the development budget of the MOH. In summary, the Ministry of Health Public Expenditure Review (GoK, 2004b) reported that the flow of funding to health facilities, especially at the primary care level as being poor with high incidences of leakage estimated at 22 of the user fee revenue collected. Perceptions about the relative efficiency and effectiveness of existing spending, the budget execution issues mentioned above and the feeling that the sector is already well catered for by donors, is likely to have had an impact on the reluctance of the government to substantially increase health funding. Given the current global financial crisis, it appears unlikely that significant additional external resources will be available, and there may even be some reductions in allocations by some donors.

On the other hand, NHIF resources accounts for about $10 \%$ of public health spending. Services are purchased from only a few facilities with government hospitals constituting $65 \%$ while the remaining $35 \%$ constitute faith-based, private and community-based hospitals (GoK, 2010). NHIF has continued to accumulate huge surpluses due to under-utilization of the contributions. This under-utilization is attributed to many factors. These include: i) the narrow benefit package (which has not been expanded despite the legal changes of 1998), ii) lack of incentives for public sector providers to seek reimbursements; and iii) bureaucracy and sloppy management of the funds. Although the share of contributions devoted to providing benefits has increased in recent years, in 2007/08, it was only $45 \%$, and in view of NHIF's wide network, administration costs account for a large share of revenue. Efforts to replace the NHIF with the National Social Health Insurance Fund (NSHIF) in 2006/07 were unsuccessful when the Act failed to receive presidential assent. The fund is in the process of piloting out-patient cover with the intention of rolling over to the entire membership.

\subsection{Current Sources of Health Care Financing in Kenya}

\subsubsection{Out-of-Pocket Spending}

In the country, out-of-pocket (OOP) spending generates the largest proportion of the revenue used to access healthcare services. This source contributed $52 \%$ and $36 \%$ of all the health expenditures in the country in 2002 and 2005, respectively. These funds are used directly at the point of accessing healthcare and are therefore subject to their actual availability at the time of illness, and the cost of the services. At least $65 \%$ of these funds are destined for use in the private sector. The Ministry of Health is the second most important source of funding, contributing to about $30 \%$ of all health expenditures in the country (almost exclusively for use in the public sector). Resources from development partners are principally channeled to support direct expenditures in programmes and projects, particularly those of a non-curative nature. A small proportion of Kenyans have their health resources channeled into the system though NHIF and private health insurance especially those in formal employment. The principal feature of the collection process is that it is fragmentary, unpredictable and except for NHIF, there is no legal or formal provision for how much may be contributed from any of these sources. Consequently the poor who in most cases are unemployed or employed in the informal sector may be not assured of accessing healthcare services when they are sick. This is because the government has not been consistent in meeting its commitments to increase allocations to the health sector (GoK, 2010). In general, heavy reliance on OOP spending as a source of healthcare financing, remains a major barrier to access, with majority purchasing poor quality health services in the end.

In terms of access the large majority of Kenyans do not have access to affordable healthcare due to poverty, currently estimated at 42 percent. According to the Household Health Expenditure Report of 2008, $44 \%$ of Kenyans who fall sick do not seek healthcare services, due to lack of finances and many of them either resort to traditional healers or simply opt to stay at home (GoK, 2008). In the report, it was observed that over $40 \%$ of the poor undertake self-diagnosis when sick and where possible resort to self-medication. Figure 2.3 provides a summary of out-of-pocket spending by wealth quintile.

Figure 2.2: Out-of-Pocket Expenditure by Wealth Quintile in Kenya 


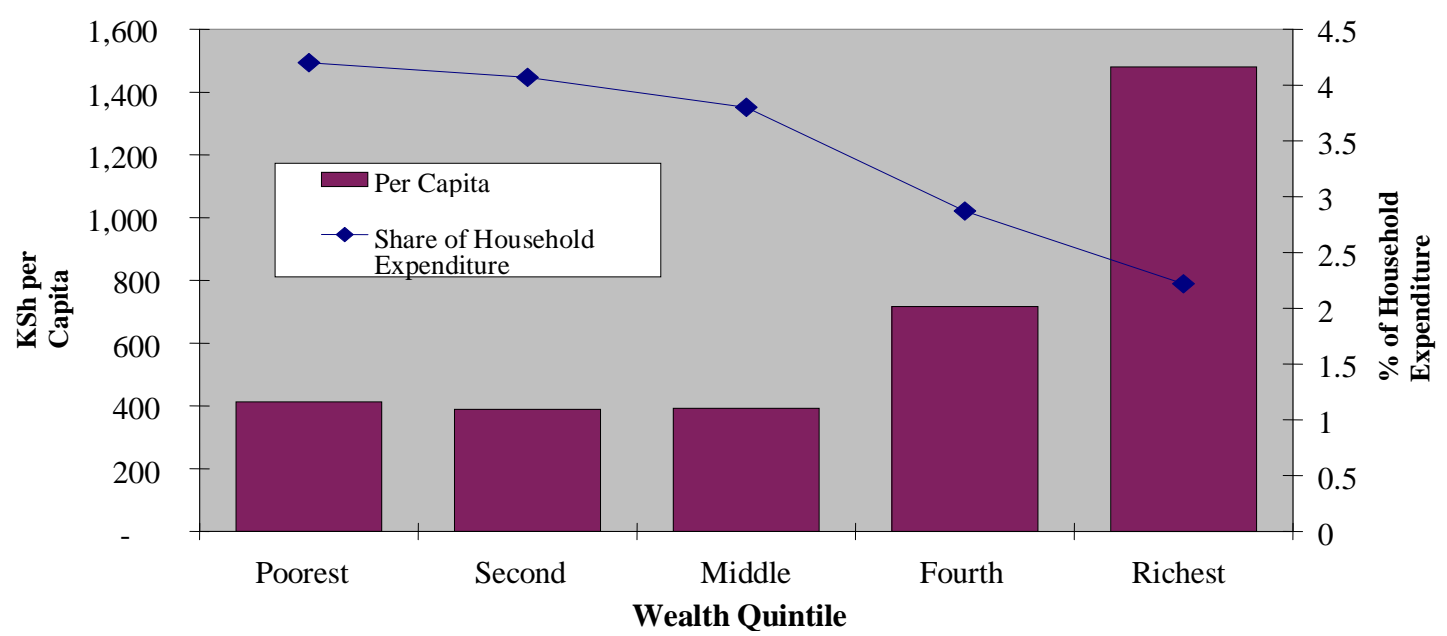

Source: Kenya Household Health Expenditure and Utilization Survey Report 2007

It is far from clear that such spending offers value for money since $69 \%$ of private spending on outpatient care is for drugs, with little or no evidence on whether this follows the practices of rational use of drugs. The share of private financing, especially out-of-pocket spending, has declined rapidly in both relative and absolute terms. According to the latest National Health Accounts, the share of private financing fell from $54 \%$ in 2002 to $39.3 \%$ in 2006, with much of this due to the increase in the share accounted for by donor support. Private spending declined in real terms by $9.8 \%$ from KSh 30.8 to KSh 27.8 billion over said period. Household spending dropped from $51 \%$ to $36 \%$ of total health expenditures ${ }^{2}$, and spending per capita (inflation adjusted) declined from KSh 770 to KSh 713. Perhaps more importantly, direct out-of-pocket spending decreased by $29 \%$ from KSh 819 to KSh 578. This huge drop in household spending mirrored a significant increase in flow of development partner funds, especially from PEPFAR, to the sector, which is however expected to suffer given the current funding schedule to developing countries including Kenya.

\subsubsection{Overreliance on User-Fees Public Facilities to Fund Services}

In 2007/08, reported cost sharing revenues amounted to some KSh 1.57 billion $(\mathrm{MoH})$. Revenues have increased dramatically from around KSh $28 \mathrm{~m}$ in 1990/91 and KSh $720 \mathrm{~m}$ in 2000/01. District hospitals accounted for just below 60 percent of total revenues and provincial hospitals almost 30\%. Collections in Central Province were more than 10 times greater than those in North Eastern Province. Although small, in absolute terms, they are significant at the operational level, accounting for $61 \%, 50 \%$ and $19 \%$ of the provincial, district and rural health facility operational budgets (excluding salaries), respectively. There has been a system of waivers and exemptions to cover children under five, TB treatment, malaria drugs, HIV/AIDS treatment and the poor, but this system is not well defined and is complex to administer, since there are no clear criteria to determine the patients who qualify. The important role for user-fees, as a mechanism for healthcare financing, is curtailed largely due to lack of third party payment for the cost of waivers and exemptions instituted to protect and guarantee access by the needy. As a result, the fee levels have been kept low, thereby undermining its revenue generating potential, and consequently its ability to support increased provision and availability of quality services.

\subsubsection{Prepayment schemes}

In the country, less than $4 \%$ of all the health funds are subjected to risk-pooling under both NHIF and private health insurance otherwise known as health management organizations (HMOs). This is an indication of insufficient cross-subsidy from among the different socio-economic groups in the country. Similarly, the purchasing of healthcare services is predominantly personalized (fee-for-service), or input-based (as line item budgets) in the public sector. As noted earlier, the public sector is not, therefore, able to channel a significant proportion of health funding to the point of neither use, nor can the low-income groups afford healthcare when they are sick.

\subsubsection{Diversity in the Availability of Healthcare Providers}

Although in Kenya there is a robust public/private mix (50:50) in healthcare service providers, due to inability of a large segment of the population to afford private sector healthcare, there is under-utilization of these services. Bed occupancy, for example, is on average under 50\% in the private sector, while in the public

\footnotetext{
${ }^{2}$ This expenditure is in the form of direct payments, payment into an insurance scheme, or by purchase of a "health card" that gives access to services for a defined period of time
} 
sector this may exceed $100 \%$. The net result is high unit costs in the private sector and poor quality of care in the public sector. Figure 2.3 shows the relative functional dominance of each of the principal players in Kenya's healthcare financing system.

\section{Figure 2.3: Financing Healthcare in Kenya}

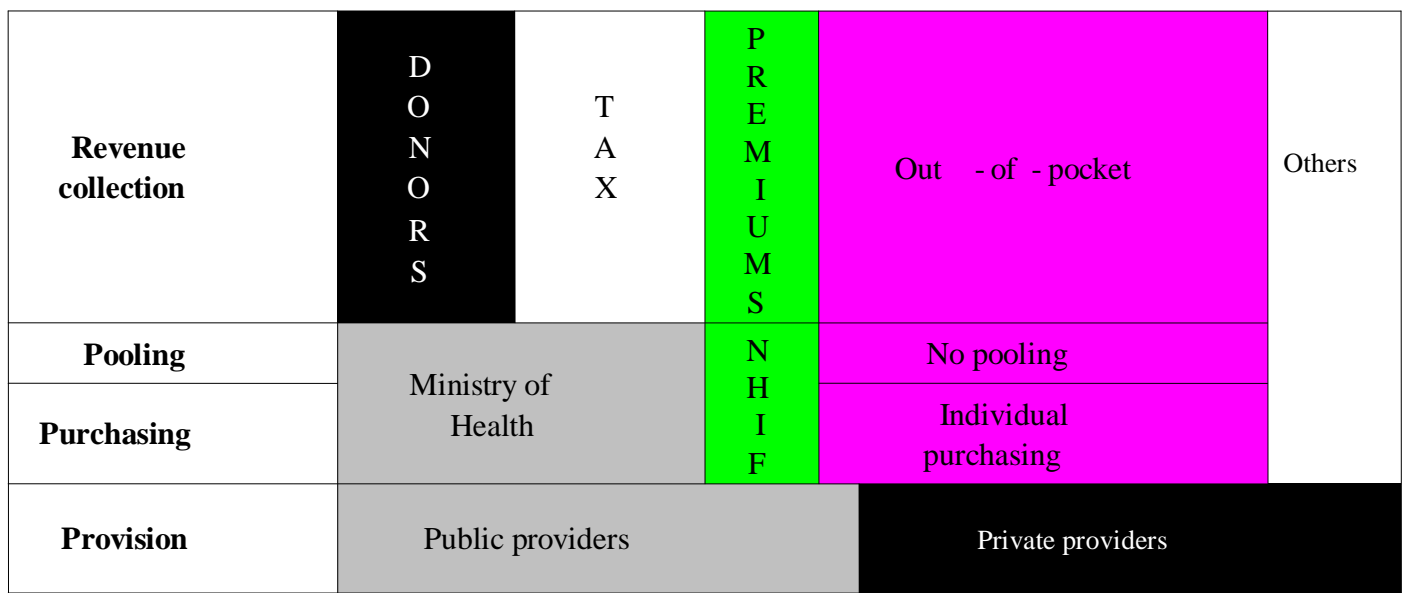

\section{Source: GoK, 2010}

Within the public sector there is a heavy concentration of authority over resources by the centre which curtails the flexibility of the districts in planning for, and using, the allocated resources. The government system of budget and cash management remains inflexible, and tends to undermine the districts' ability to utilise their budgets fully, culminating in unavailability of services. Health facilities receive much of their support in-kind with limited scope to reallocate across budget lines in ways that can ensure the available resources are used optimally to improve the availability of services. These rigidities create inefficiencies and can contribute to low budget execution. Furthermore, health workers are paid on a salary basis which, whilst good at containing costs, provides few incentives for greater productivity, or the delivery of better quality services.

Similarly, execution of public expenditures on health is characterized by relatively good execution of recurrent budgets, but under-spending of development budgets. Despite some improvements, development spending accounted for only approximately $40 \%$ of the development budget (approved printed estimates) in $2004 / 05$, and about 50\% during 2005/06, indicating problems with absorption capacity (the ability to effectively utilise the available funds) and problems of accessing development partner resources. A recent review of health expenditures revealed that the Ministry of Health $(\mathrm{MoH})$ only spent about $33 \%$ of the approved development budget; with the worst performance in the preventive and promotive health sub-vote (24\%), which received almost half of the approved development budget. Within the recurrent budget, there appears to be on-going problems with fully executing the drugs and medical consumables, and the purchase of plant and equipment categories (GoK, 2010). Poor expenditure management has resulted in many stalled development projects, and the accumulation of large sums of pending expenditures. According to the Health Sector MTEF of 2006/07 2008/09, there are also currently some KSh 2.1 billion in stalled construction projects in the MoH (completion cost), although this is down from KSh 3.5 billion in 2005 (GoK 2005).

Currently, it is estimated that there are more than 20 major donors in the Kenyan health sector (not including partner groups, self-financing NGOs and mission organizations), mostly disbursing funds through the public sector that includes the $\mathrm{MoH}$, teaching and research institutions; NGOs and other donor agencies, whose support is heavily skewed towards certain areas. A substantial proportion of donor financing supports programmes to expand access to anti-retroviral therapy and on other HIV/AIDS, malaria and tuberculosis programmes. Donor financing also caters for a large proportion of the recurrent expenditure of FBOs and NGOs. The share of aid in overall funding for health has increased dramatically and now exceeds public sector financing, making Kenya extremely vulnerable to a downturn in donor support. Its share of total health expenditure almost doubled from $16 \%$ in $2001 / 02$ to $31.6 \%$ in $2005 / 06$. It also has the potential to create significant inflationary pressures and macroeconomic distortions.

While the financing from an increasing number of development partners is shown as part of the government budget, the contributions from several others, accounting for a significant share of donor resources for health is still off-budget, with the Ministry of Health having very little control over, and even knowledge about, their expenditures. This can create distorted spending patterns, as well as the implementation of programmes that are not key priorities. There are ongoing discussions between the government and development partners to address this issue, including developing approaches for channelling resources from multiple partners through a common funding stream in support of government priorities.

It is clear from the foregoing discussion that households spending through out-of-pocket spending, and 
Empirical Analysis of the various alternative sustainable....

donors remain the largest contributors of health funds. The private sector, which comprises of households, private companies, and local foundations, contributed 39\% of total health expenditure, with $36 \%$ coming from households, mainly through out of pocket spending in year 2007/08 (NHA, 2009). Such systems of health financing make it impossible to spread costs over the life-cycle: paying contributions when one is young and healthy and drawing on them in the event of illness later in life. Consequently, the risk of financial catastrophe and impoverishment is expected to be high, and achieving universal coverage becoming unattainable. Based on this, the study sought to examine the public perception of the financing mechanisms for health care services in Kenya.

\subsection{Health Personnel, Infrastructure and Providers}

The availability and comprehensiveness of health services offered at a health facility depends, in large part, on the number of health workers at that facility. According to the Human Resource for Health Strategic Plan (HRHSP, 2007-10), there are overall staff shortages with 47,247 personnel, against an estimated minimum requirement of about 72,234. Shortfalls are heavily concentrated in parts of Coast, North Eastern Rift Valley and Nyanza Provinces; areas that that have the lowest health indicators. Since 2005, a concerted effort has been made to increase the number of skilled health workers available at the lower levels of the health system with the intention of enhancing access to PHC. These efforts have however, not produced the desired impact in terms of realizing desired health outcome as well moving towards the realization of MDGs to which Kenya government is a signatory. Nonetheless, government personnel remain heavily skewed in favor of hospitals and the better-off districts. Part of the overall problem can be traced to difficulties in recruitment and retention including: incentives for locating in hard-to-reach places, general motivation and incentives, and human resources management. As a result, several public health facilities remain closed due to shortfalls in human resources (GoK, 2010; Gitahi, 2011). In addition, many public hospitals are dilapidated and do not have access to appropriate equipment. Concurrently, there are significant gaps in essential specialised care capacity forcing individuals to seek these services abroad when required.

To circumvent resource flow bottlenecks and to devolve financing in the country, parliament introduced the Constituency Development Fund (CDF), through which earmarked government allocations are made to each constituency on the basis of a formula that is heavily weighted on poverty levels. The use of CDF resources has also added to the infrastructure in an ad hoc way, with facilities developed with little reference to outstanding needs, or the ability to meet on-going recurrent requirements, which must be met from $\mathrm{MoH}$ resources. Healthcare services are currently provided not only by public facilities, but also by FBO, NGO and private-for-profit providers. In fact, in the latest NHA, 39.6\% of the cost of health services was managed by non-public providers. To date, little effort has been made to rationalise the service delivery network in the country, contributing further to access problems.

In terms of providers, the country exhibits a robust public/private mix (50:50) in healthcare service providers. Due to inability of a large segment of the population to afford private sector healthcare services primarily attributed to high poverty levels in the country, there is under-utilization of these services. Bed occupancy, for instance is on average under $50 \%$ in the private sector, while in the public sector this may exceed $100 \%$. The net result is high unit costs in the private sector and poor quality of care in the public sector (GoK, 2010). Available statistics the 2003 Household Expenditure and Utilization Survey Report shows that the poor utilize health care services and that majority of these vulnerable persons are less likely to seek treatment when ill, compared to the more well-off. Figure 2.4 shows significant variations in utilization of out-patient care between provinces and between urban and rural areas in the country.

Figure 2.4: Utilization of Health Services by Geographical Location and Wealth Status

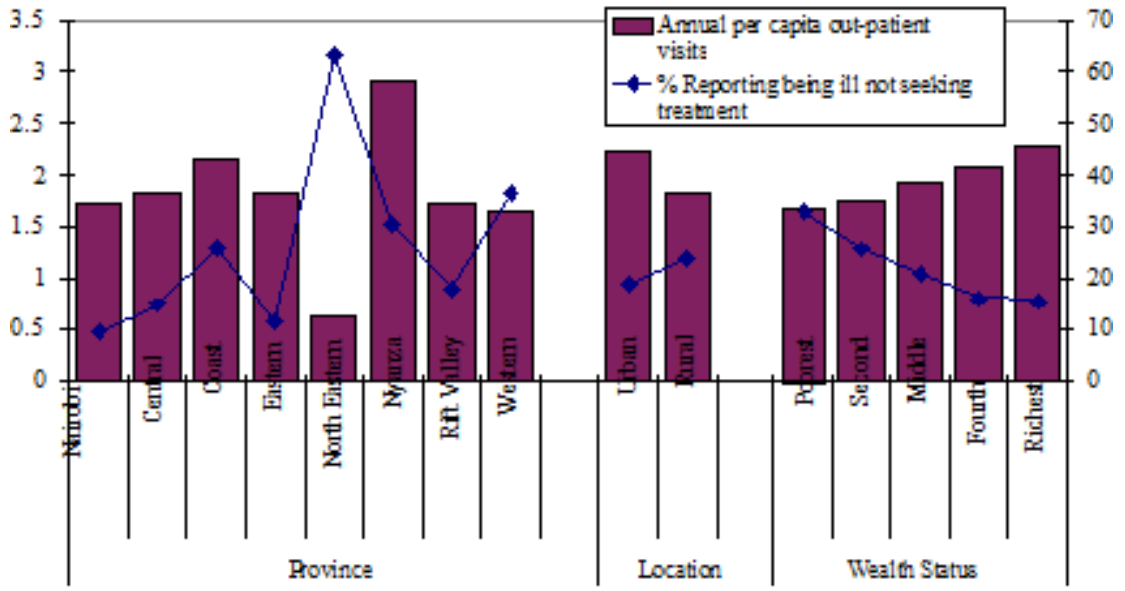


Empirical Analysis of the various alternative sustainable....

\section{Source: GoK, 2010}

This pattern is also consistent for in-patient care with the rich individuals, on average, making 20 admissions per 1,000 of the population annually, compared to 14 for the poorest quintile. These variations are attributed to the cost of services. Studies also show that the poor are much more likely to use public facilities, especially for inpatient care.

\subsection{Possible Alternatives Financing Mechanisms for Public Health Care}

In this sub-section, various possible financing mechanisms are reviewed. These include risk-pooling (including micro-insurance, community based health insurance, social insurance, among others), dedicated taxes and infrastructure bonds as some of health financing mechanisms are briefly discussed.

\subsection{Specific Tax levies for health care financing}

In various parts of the world, special taxes have been introduced specifically to finance health care reforms in general and health care financing in particular. This is because the mechanism has the capacity to generate adequate financial resources and it has a relatively low cost of collection. In the US for instance, an additional US\$ 10 billion annually for global health is raised through the introduction of a tax on air tickets, foreign exchange transactions, tobacco and alcohol consumption (TIIFHS, 2009). Other sources include a range of products and services, such as mobile phone calls, imported luxurious products, sugary drinks and foods high in salt or transfats (Leonhardt, 2010; Holt, 2010; Musango and Aboubacar, 2010; Stenberg et al., 2010). For instance, introduction of tobacco taxes in some states in Australia in 1983 resulted in a considerable injection of funds for health promotion which generated US\$1.2 million which was in the process directed to the "Tobacco Tax Trust Fund' (Holman et al., 1984).

Similarly, in Californian voters approved 25 cents per package increase on cigarette tax in 1988, a quarter of which was earmarked for anti-smoking education and tobacco-related research (Bal et al., 1990. In Stenberg et al. (2010), it was estimated that levying such taxes would lead to a reduction in consumption of alcohol by more than $10 \%$, while tax revenues would more than triple to a level amounting to $38 \%$ of total health spending especially in low income countries (LICs). This could be attributed to habitual nature of these products and their inelasticity of demand. Ghana, for example, covers $70-75 \%$ of funding needs for its National Health Insurance Scheme with general tax funding, notably through a $2.5 \%$ national health insurance levy on VAT estimated at $12.5 \%$ (Witter and Garshong, 2009). Chile on the other hand, introduced a 1\% increase in VAT in 2003 to finance public health. The VAT-based National Health Insurance Scheme has been able to support an increase in total health expenditure through domestically generated pooled funds. At the same time it has lessened the system's dependence on direct payments such as user fees as a source of finance (Tsounta, 2009). Analysis by WHO on the potential gains from increasing taxes on tobacco in 22 of the 49 LICs shows that an excise taxes in these countries range from $11 \%$ to $52 \%$ of the retail price of the most popular brand of cigarettes, representing a nominal range of US\$ $0.03-0.51$ per pack of 20 . If these are considered, a $50 \%$ increase in tobacco excise taxes would generate US\$ 1.42 billion in additional funds in these countries. These taxes are however not universal and therefore governments will need to implement those that best suit their economies

Studies show that the success of these schemes depends on political. For instance, Gabon imposed a $1.5 \%$ levy on the post-tax profits of companies that handle remittances and a $10 \%$ tax on mobile phone operators raising an equivalent of US\$ 30 million for health in 2009 (Musango and Aboubacar, 2010; Stenberg et al., 2010). Similarly, the Pakistan government has been taxing the profits of pharmaceutical companies to finance part of its health spending for many years (Nishtar, 2010). This is thus an indication that there is the potential to increase solidarity taxes on specific goods and services exist in many low income countries. In practice, however, a country like Kenya which has a large informal sector tend to focus on taxes that are relatively easy to collect, especially in the formal-sector especially employees and corporations, import or export duties of various types and value added tax (VAT).

It is noteworthy that governments and ministries of finance in particular, are generally not enthusiastic about earmarking taxes for specific purposes as pointed out by Busse (2007). As a result, this should be carefully done because earmarking some products can be politically sensitive and will invariably be resisted by particular interest groups. A tax on foreign exchange transactions, for example, may be perceived as a peg on the banking sector or as a disincentive to exporters/importers which may be perceived have significant on generation of revenue for the central government. For instance when Gabon introduced a tax on money transfers in 2009 to raise funds to subsidize health care for low-income groups, some people protested that it constituted an exchange restriction.

\subsection{Infrastructure Bonds}

Bonds are considered as long term debt financing, which may cater for the long term investment expenditures such as expansion, rehabilitation and refurbishment of the dilapidated health infrastructure or the or construction of new health facilities. General bonds are issued and guaranteed by the central government. Traditionally, governments issue Treasury Bonds to finance public expenditure. For instance in 2009, the 
Kenyan government launched the first infrastructure bond (a 12-year bond) worth Kshs. 18.5 billion to finance water, sewerage and irrigation, roads and energy projects (Central Bank of Kenya, 2009). To attract investors, the government included incentives such as withholding tax exemption on interest income and listing at the Nairobi Stock Exchange - this would increase the bond's liquidity.

In some instances, municipal bonds may be issued by the local authority as a way of helping local governments, particularly urban governments to finance critical infrastructure with domestic private capital, rather than sovereign borrowing by central governments. These bonds are usually exempted from taxes. Although health care projects in developing countries have not tapped into the bond market, the sale of bonds in international bonds market has mostly been available to large projects by donor countries where issuance of these bonds has raised more than US\$ 2 billion since 2006 [International Financing Facility for Immunization (IFFIm), 2010].

\subsection{Prepayment Schemes}

These include risk pooling schemes such as health insurance which are considered as being fundamental in improving domestic health financing as a bold step towards the realization of the health related MDGs in an equitable way. People contribute to a pool that they, or others, can draw on in the event of illness. According to World Health Report (WHR) of 2010, pooled funds are effective especially since they can cover prescription medicines, ambulatory care, hospitalization, disease prevention and health promotion all of which are critical components of PHC. Using this kind of funding, incidence of financial catastrophe, impoverishment and the inability to access quality care are likely to fall to negligible levels especially among the poor.

This method has been embraced by many countries due to the failures of the user payments schemes that countries adopted in the last there decades. These have been implemented on a small scale in various countries including Rwanda, Ghana, Ethiopia and they have been successful in enhancing access to quality care while at the same time mitigate against catastrophic health expenditure especially among the poor in the society. Although this seem to work in various world economies, there will be need to caution the poor who may not be able to pay the necessary premiums. Additionally, the success of these mechanisms will however, depend on how the public including the private sector insurance conceives the idea and the ability to minimize the expected transaction costs including management and collection of the funds.

\subsection{Methodology and Findings \\ 4.1 Methodology}

To secure a representative sample, a descriptive research design was employed to ensure the assessments of the target population that would represent the general population. The research design was appropriate for this study as it allowed for the analysis of the views of health care personnel involved in financing of health care. Both interview schedule and a self administered structured questionnaire were used in collecting primary data. Additional data was collected from secondary sources including the ministry's strategic plans, draft financing strategy as well as Kenya Vision 2030 and MTEF. Others were relevant journals, published authoritative and WHO and World Bank publications. Data collected was cleaned and validated before being coded in a mode that could be picked by the necessary statistical package. Finally, the analysis was conducted using Statistical Package for Social Scientists (SPSS) and MS Excel in terms of frequency tables, charts and graphs.

\subsection{Findings and Discussion}

Reported in this sub-section are the various financing mechanisms discussed above. The first subsection provides the views of respondents in terms of risk-pooling followed by dedicated taxes and finally issuance of infrastructure bonds earmarked for health financing.

\subsubsection{Prepayment Schemes}

Respondents expressed their support for prepayment schemes as these would facilitate risk pooling mechanisms that could provide a viable financing mechanism capable of protecting the poor from financial catastrophe. This according to the respondent would enhance solidarity necessary in building a wider movement towards universal coverage, especially for the poor, while at the same time reduce financial risks associated with illness. Respondents also noted that the scheme is progressive in that the rich would pay for the poor while the healthy would pay for the sick. Notwithstanding this almost all the respondents contended that the sick should not pay a significant share of the costs of health services that they use. According to the respondents necessary mechanisms were inevitable to assist the poor in paying the requisite premiums in order to caution the poor who could not afford the premiums.

Regarding contributions, all the respondents reiterated that the contributions should be compulsory with subsidies for the poor. According to the respondents, if the contributions are voluntary the rich are likely to seek individualist health insurance from private insurance companies and as a result minimal resources will be generated. In the process the intended objective of cautioning the poor and other vulnerables against financial catastrophe would be elusive. Longer-term plans for expanding prepayment and incorporating community as well as micro-insurance schemes were proposed in order to broaden the resource envelop. Respondents however 
noted that reaching informal sector has been a challenge with the cost of collection surpassing the revenue collected. Respondents further noted that efforts need to be initiated in order to reach informal workers and farmers. Smaller risk pools in the form of community health funds may were thus proposed. However, according to the respondents would require enhancing the capacity in order to determine the appropriate/minimum premium levels for such schemes, as well as for the general population of insured persons covered through formal employment, or other informal group arrangements.

\subsubsection{Specific Tax levies earmarked towards financing health care}

With regard to specific tax levies, various divergent views were expressed. Whereas majority of the respondents were of the opinion that specific taxes be introduced to raise adequate financial resources to improve people's health, a few felt that this would not be a good solution for Kenya at this time. One argument against such taxes is that it constrains the overall fiscal space of the government, and gives rise to similar requests from other sectors. For those who supported this mechanism, they observed that it provides a stable revenue stream, whose cost of collection is relatively low for the government if necessary institutional structures are initiated and implemented. Whereas these findings are in line with the findings by Prakongsai and Patcharanarumol (2008); Gordon (2009); Stenberg et al (2010); UNITAID (2010); Fryatt (2010); and Nishtar (2010), they contradict the findings by Lucas (1998). For instance where as Prakongsai et al (2008) noted that key attribute of an ideal specific tax fund is raising more funds and improving health at the same time reducing consumption of harmful products such as tobacco or alcohol, Lucas (1998) noted that such new funding mechanisms attract a high level of interest and scrutiny by government, interest groups such the media,the community, private sector and lobby groups which in the process may hamper its administration. Lucas further observed that policy-makers and others tend to have high expectations of what may be achieved by the new funding in the short or even medium term. For instance, they may expect that the fund will demonstrate a contribution to economic development, as well as measurable health improvements, in a relatively short time. Such expectations are unlikely to be realized and may be damaging if not corrected. Respondents were however, quick to note that implementing these kind of taxes should be done systematically by first identifying the products that should be targeted for taxation followed by the necessary consultation with key stakeholders such as politicians, the media, health professionals, key opinion leaders and the general community to get their buy-in otherwise it is likely to be contested in public as well as the court of law which in the process may send inappropriate signal in the implementation.

This is because according to the respondents, some products could be politically sensitive and will invariably be resisted in the process. Additionally, taxes have distortionary effect which may be viewed to contribute towards deadweight loss to various economic agents. The respondents further observed that once these have been accomplished, then the case for dedicating part of funds for specific health programmes can be initiated with the necessary legal framework. Finally, specific organ to administer the generated resources need to be estimated with the necessary management structures for prudent financial management. The study further revealed that lack of judicious implementation of a dedicated tax fund would suffer from various challenges. Among them opposition by the companies affected, as well as the Ministry of Finance and by the agencies such as sports which are funded by the companies affected. In terms of specific target products, a large majority of the respondents were of the opinion that tobacco, airtime, air ticket, remittances from the Diaspora, unclaimed assets in financial institutions and alcoholic drinks should be subject be the first target. Other products suggested by respondents were sugary drinks and foods high in salt due to their health hazards.

\subsubsection{Health Bonds}

Innovative modalities for generating revenue, particularly to cover the health needs of the poor, will be are critical. This includes the option of a health bond and promoting health savings. This is important in the country as most health facilities are in need of rehabilitation while many cannot handle special cases. A large majority of the respondents supported debt financing through issuance of infrastructure bond due to its longterm repayment period. The preference according to respondents was associated with the history of the Kenyan government's use of government guaranteed debt financing with the recent infrastructure bond to finance both rail and road networks. Although revenue from municipal bonds may still be acceptable, only a minority were in its favor. This according to the respondents was due to the local government's ability to settle their debts in time and, notwithstanding investors' nature of being risk averse. This findings is supported by the recently released statistics by the Ministry of Local Government that revealed that local authorities in Kenya are in arrears to the tune of about Ksh 18 billion with only a few capable of meeting recurrent obligation including salaries and wages. This therefore means that their ability to repay debt obligations when they fall due are limited and questionable.

Other key issues raised for the success of the facility were level of development of the bond, government guarantee, the ability to sell the bond before maturity, nature of information asymmetry regarding bond risks, tax treatment of investor returns and credit rating of the issuer. The study also revealed that bonds offer several benefits to the issuer including reduced borrowing costs, increased investor base for infrastructure, 
provision of a means of raising large sums of money, assisting to diversify sources of funding, and establishing a favourable credit history in the capital markets. In terms of the need to issue part of the initial infrastructure bond to a reputable investor, such as the World Bank, to boost investor confidence, the response was that having such an anchor investor in the Kenyan market was of little importance. However, the fact that Kenyan investors have demonstrated their willingness to purchase infrastructure bonds may imply that there is sufficient investor confidence and hence no need for an anchor investor in the Kenyan infrastructure bond market.

\subsubsection{Other financing mechanisms}

Respondents also suggested other financing options as a bold step towards enhancing access to quality public health care. These included:

i) Improving efficiency, accountability and transparency by reducing and changing the role of the State, Ensuring Services are of adequate quality, strengthening the referral system, making more effective use of the private Sector;

ii) Strengthening revenue collection through the establishing a new revenue collection agency to ensuring that the maximum amount of funding is available for purchasing health services,

iii) More effective risk-pooling mechanisms such as community and micro-insurance;

iv) Harnessing the informal sector financing potential by incorporating entrepreneurs, self-earning professionals, members from the matatu sector, agricultural sector, the juakali sector and freelance workers into the NHIF;

v) Broadening the benefits package by NHIF to cover both the in-patient and out-patient costs;

vi) Strengthening provider incentives by developing new approaches to reimbursement; and

vii) Establishing measures for protecting the poor and vulnerable groups by first establishing mechanisms for identifying the poor, strengthening the provision of health services to poorer groups, initiating mechanisms for covering the cost of the poor.

\subsection{Conclusion and Way Forward}

\subsection{Conclusion}

Based on the findings and literature reviewed, it is clear that there are valiant mechanisms for financing PHC in Kenya. These include but not limited to establishment of prepayment schemes, establishing a specific tax levies, issuance of health bonds, enhancing revenue collection as well as establishing mechanisms that wuld protect poor and other vulnerables from access quality care. For instance, prepayment schemes through risk pooling would facilitate in spreading the cost of health care and reduce incidences of financial catastrophe and increase in utilization of health services among the poor in the society. Specific tax funds, on the other hand, would provide a stable revenue stream for financing health care, promote and protect peoples' health. This according to the respondents however, requires establishment of the necessary legal framework that will spearhead the required reforms. The respondents however, cautioned that the success of mechanism will depend on the ability to identify the products on which the tax will be levied followed by an all inclusive consultation with key stakeholders for consensus building and avoidance of cases of public outbursts that may affect the collection of the funds. Additionally, establishment of the necessary legal framework upon which the scheme will be anchored including establishment of the organization to spearhead the process was a key issue raised.

Other additional financing options that were favored by respondents based on the study findings include improving efficiency, accountability and transparency, harnessing the informal sector financing potential, Broadening the benefits package by NHIF to cover both the in-patient and out-patient costs; and strengthening provider incentives by developing new approaches towards reimbursement.

\subsection{Way Forward}

The success of prepayment involves making the contributions compulsory. However, given the poverty levels estimated at $42 \%$, there is a segment of the population that may not afford the charges. Therefore, it will be necessary that safety nets are designed to cushion this group. Thus the government with support from donors through the proposed Joint Financing Agreement (JFA) could be considered in introducing Health Equity Funds (HEFs) like in the case of Cambodia or micro-insurances in Rwanda. These however, require capacity building at local level to manage the schemes and also to minimize on transaction costs unlike in the case of Cambodia where in the initial phase, the scheme was entirely managed by expatriates. As a first step towards this, it will be necessary to design a tool that will facilitate in the identification of the poor. The tool developed for National health Insurance Fund (NHIF) by Okumu (2012) could provide some basis of developing a tool for use nationwide. In terms of specific tax levies, it is necessary that wider consultations are embraced to minimize incidences where these funds are challenged both legally and politically. Legal framework needs to be established so that the scheme is anchored onto the laws of the country. This should be considered alongside the establishment of a legal entity that will prudently manage the funds collected.

Additionally, both political and leadership commitment is necessary in order to promote budgetary allocation towards health sector in line with the Abuja Declaration of 2001. With the increased funding, it will necessary to address supply factors such as access in terms of physical, coverage and utilization, quality of 
services in terms of the health package, availability of drugs, quality of personnel and their availability, availability of necessary equipment, among others. Alternative flow of funds arrangements may therefore be needed to ensure that allocated funds reach service providers in this regard, donors may need to not only support the design but also the operationalization of revenue management schemes at all levels of public revenue spending. Mechanisms to ensure that public funds actually reach their intended target need to be promoted. Wastage and corruption in the health sector are widespread and substantial resources could be mobilized for the provision of services by increasing the transparency and accountability of public sector resource management.

To address the problems associated with health facilities, the government needs to embark on the rehabilitation and refurbishing of public hospitals to ensure that these institutions meet the minimum acceptable Certification Standards. This will also necessitate the provision of additional equipment and ICT facilities to all hospitals. Lastly, an efficient revenue collection system is critical to ensuring that the maximum amount of funding is available for purchasing health services. Since the active purchasing function is so complex, and so important to the smooth functioning of the healthcare financing system, it makes sense to separate the revenue collection and purchasing functions. Therefore, one agency can focus on maximizing the amount of revenue, while another can focus on deriving maximum value from the available revenue. This is done automatically under the current tax funded model. Under a social insurance model, the government would need to consider establishing a joint agency to collect all social security related contributions especially those associated with specific taxes.

\section{REFERENCES}

[1]. Bal D.G., et al. (1990). Reducing tobacco consumption in California. Development of a statewide anti-tobacco use campaign. Journal of the American Medical Association. 264:1570-1574.

[2]. Carrin, et al. (2008) .Universal coverage of health services: tailoring its implementation. Bull World Health Organ; 86:857-63. Chris, J. \& William, D. (2010). Risk pooling and redistribution in health care: an empirical analysis of attitudes toward solidarity. World Health Report (2010) Background Paper, No 5.Commission for Africa. Our common Commission for Africa. Our common interest. London: Commission for Africa, 2005.

[3]. Craig, H. (2010). Health care facilities, construction gets easier with the new financing (412) 288-7344; Mark.Blasinsky@fhlbpgh.com.Government of Kenya (2008). Republic of Kenya: Budget Speech for the 2008/2009 Fiscal year, Nairobi, Government Printer.

[4]. Government of Kenya (2008). National Health Sector Strategic Plan II. Nairobi, Government Printers

[5]. Government of Kenya (2002). Facility Improvement Fund-Supervision Manual, Nairobi: Government Printer.

[6]. Government of Kenya (2003). Economic Recovery Strategy for Employment and Wealth Creation (2003-2007), Nairobi: Government Printer

[7]. Government of Kenya (2010). Accessible and Affordable Quality Healthcare services in Kenya, Financing Options for Universal Coverage, Nairobi: Government Printer

[8]. Hyun S., Nishizawa T. \& Yoshino N. (2008). Exploring the Use of Revenue Bond for Infrastructure Financing in Asia. JBICI Discussion Paper No.15. Japan Bank for International Cooperation: Tokyo.

[9]. Mobile phone voluntary solidarity contribution (VSC). Taskforce on Innovative International Financing for Health Systems Factsheet, $2010 \quad$ (http://www.internationalhealthpartnership.net//CMS_files/documents/factsheet_-_ mobile_phone_voluntary_solidarity_contribution_EN.pdf, accessed 30 Jan 2011)

[10]. Musango, L \& Aboubacar, I. (2010). Assurance maladie obligatoire au Gabon: un atout pour le bien-être de la population. World health report, background paper, no. 16. of welfare effects of User Fees. Social Science and Medicine 22: $763-767$.

[11]. OAU. (2001) Abuja declaration on HIV/AIDS, tuberculosis and other related infectious diseases, Addis Ababa, Organization of African Unity.

[12]. Prakongsai, P., Patcharanarumol, W. \& Tangcharoensathien, V. (2008). Can Earmarking mobilize and sustain resources to the health sector? Bulletin of the World Health Organization, 86:898-901

[13]. Ritthiphakdee, B. (2002). Tobacco taxation and dedicated tax; a win-win strategy for tobacco control. Thailand's experience. Paper presented at the INB 5 Meeting, Geneva, 2002.

[14]. Stenberg, K et al. (2010) Responding to the challenge of resource mobilization - mechanisms for raising additional domestic resources for health. World health report, background paper, no. 13.

[15]. WHO. (2001). Macroeconomics and health: Investing in health for economic development, Geneva, World Health Organization.

[16]. WHR. (2010). Health system financing: the path to universal coverage. World Health Statistics. (2010).

[17]. WHR. (2010). Thresholds of health expediture for protecion against financial risk

[18]. World Bank. (1990). World development report, 1990: Poverty. New York: Oxford Press.

[19]. Xu, K et al. (2010). Financial risk protection of national health insurance in the Republic of Korea: 1995-2007. World health report 2010 background paper, no. 23 . 